\title{
Aportes al debate en torno al incremento de la remuneración mínima vital
}

\section{Fernando Cuadros Luque ${ }^{*}$
Sergio Quiñones Infante}

La regulación laboral y, en específico, el de la remuneración mínima representa un tema álgido en un contexto en el que los procesos de negociación económica y de apertura al mercado marcan la pauta. Los autores, valiéndose de un análisis de la experiencia comparada, analizan el impacto del aumento del salario mínimo en los índices de crecimiento y lucha contra la pobreza, teniendo en consideración los aspectos legales y económicos que justificarían la adopción de esta medida.

Licenciado en Economía por la Universidad del Pacífico. Especialista en economía laboral. Profesor del curso Políticas Públicas Laborales y Responsabilidad Social Empresarial de la Maestría en Derecho del Trabajo y de la Seguridad Social de la Pontificia Universidad Católica del Perú. Se ha desempeñado como Asesor en el Gabinete de Asesores de la Alta Dirección del Ministerio de Trabajo y Promoción del Empleo y como Asesor del Consejo Nacional de Trabajo y Promoción del Empleo. Actualmente se desempeña como Especialista de la Gerencia de Políticas de Gestión del Servicio Civil de la Autoridad Nacional del Servicio Civil.

** Abogado Consejero del Área Laboral de Miranda \& Amado. Magíster en Trabajo y Política Social por la Universidad Autónoma de Barcelona. Profesor de Derecho del Trabajo en la Facultad de Derecho y en la Maestría de Derecho del Trabajo en la Pontificia Universidad Católica del Perú. Consultor de la OIT. 


\section{Aportes al debate en torno al incremento de la remuneración mínima vital}

"And because workers are people, wages are not, in fact, like the price of butter and how much workers are paid depends as much on social forces and political power as it does on simple supply and demand. ${ }^{\text {"t }}$

\section{Introducción ${ }^{2}$}

El próximo mes de mayo del año en curso se debatirá en el Consejo Nacional de Trabajo y Promoción del Empleo el eventual incremento de la remuneración mínima vital en el Perú. Como suele pasar con los diversos temas relativos al empleo, a la productividad y a los derechos laborales en general, este también ha venido siendo objeto de múltiples análisis tanto en foros académicos y gremiales, como en la prensa escrita.

Ciertamente, resulta difícil discernir con claridad cuándo las opiniones en torno a un tema altamente sensible desde el punto de vista político y social -como es el de la remuneración mínima- responden a posiciones ideológicas o a criterios estrictamente técnicos; o, como suele pasar frecuentemente, cuándo estos últimos responden a una relación causal con las primeras.

No obstante la dificultad advertida, nuestro propósito en el presente artículo es aportar un conjunto de argumentos técnicos de carácter jurídico y económico al debate que en el corto plazo se iniciará en el seno del Consejo Nacional de Trabajo y Promoción del Empleo.

A tal efecto, en las siguientes páginas abordaremos el marco normativo constitucional e internacional que justifica la existencia válida de una remuneración mínima en el país y lo complementaremos con el análisis del carácter político-social que impulsa y soporta el debate en torno a su incremento, para finalmente profundizar en las razones de índole económica que justificarían -en nuestra opinión- el incremento del salario mínimo en el Perú.

\section{Marco normativo constitucional e internacional}

La Constitución Política del Perú reconoce en el artículo 24 que "el trabajador tiene derecho a una remuneración equitativa y suficiente, que procure, para él y su familia, el bienestar material y espiritual". Agrega el citado artículo que el pago de la remuneración y de los beneficios sociales del trabajador tiene prioridad sobre cualquier

1 Krugman, Paul, 'Walmart's Visible Hand". En: The New York Times, 2 de marzo, 2015.

2 Los puntos de vista expresados en este documento de trabajo corresponden a los de los autores y no reflejan necesariamente la posición de las entidades donde actualmente laboran. 
otra obligación del empleador, y que "las remuneraciones mínimas se regulan por el Estado con participación de las organizaciones representativas de los trabajadores y de los empleadores"(el énfasis es nuestro).

Ahora bien, toda vez que la Cuarta Disposición Final y Transitoria de la Constitución establece que los derechos y libertades reconocidos en ella deben ser interpretados de conformidad con los tratados y acuerdos internacionales en materia de derechos humanos ratificados por el Estado peruano (lo que doctrinal y jurisprudencialmente se denomina "bloque de constitucionalidad"), resulta pertinente en este punto recordar que el numeral 3 del artículo 23 de la Declaración Universal de los Derechos Humanos reconoce al trabajador el derecho a una remuneración equitativa y satisfactoria que le asegure -a él y a su familia- una existencia digna.

En la misma línea, el artículo 7 del Pacto Internacional de Derechos Económicos, Sociales y Culturales, dispone que los trabajadores tengan derecho a una remuneración igual por trabajo de igual valor, sin distinciones de ninguna especie; mientras que el artículo 7 del Protocolo Adicional a la Convención Americana sobre Derechos Humanos en materia de Derechos Económicos, Sociales y Culturales, reconoce que los Estados parte se comprometen a garantizar en sus legislaciones nacionales una remuneración digna, decorosa, equitativa e igual sin ninguna distinción por un trabajo de igual valor.

Así, el derecho a una remuneración mínima que la Constitución reconoce en favor de las y los trabajadores debe interpretarse y formar un "bloque de constitucionalidad" con los instrumentos internacionales de derechos humanos aprobados y ratificados por el Estado peruano que hemos enumerado previamente; asimismo, las obligaciones internacionales de otra índole que el Perú ha asumido, como por ejemplo, las de carácter comercial en el marco de los Tratados de Libre Comercio (TLC) celebrados con los Estados Unidos de América, la Unión Europea o Canadá, constituyen también parámetros jurídicos vinculantes a tener en consideración frente a cualquier debate que involucre el incremento del salario mínimo en el país.

Efectivamente, los TLC antes mencionados incluyen disposiciones relativas a la "garantía de condiciones aceptables de trabajo respecto a salario mínimo", como lo señala el artículo 17.8 del TLC con los Estados Unidos de América, por ejemplo; o al reconocimiento de "el empleo productivo y el trabajo decente para todos como elementos claves para gestionar el proceso de globalización", como lo dispone el artículo 269.1 del TLC con la Unión Europea; así como al pleno respeto a la Constitución y las leyes laborales con el objetivo de mejorar las condiciones de trabajo y los niveles de vida en el territorio de cada Estado parte, como es el caso de los artículos 1601 y 1602 del TLC suscrito con Canadá.

Nótese que si bien es cierto que los acuerdos comerciales antes citados no tienen como finalidad explícita la regulación de las condiciones laborales -como claramente se 
ve reflejado en sus respectivos articulados-, no es menos cierto que todos ellos reconocen la crucial relevancia que tienen el tema laboral -en general- y el de los salarios, -en particular- para el desarrollo sostenible del comercio internacional.

En síntesis, el derecho constitucional a una remuneración mínima y la obligación del Estado de regularla forman parte de un conjunto de derechos humanos fundamentales reconocido en los principales instrumentos internacionales ratificados por el Estado peruano, a la par que constituyen en la actualidad elementos prioritarios en el marco de los procesos de apertura al libre comercio de los que el Peru viene siendo parte desde hace una década.

Dicho lo anterior, resta complementar el panorama jurídico antes descrito con lo señalado recientemente por el Tribunal Constitucional (TC) en la Sentencia 001-014-PI, recaída en el Expediente 0020-2012-P1/TC (Demanda de inconstitucionalidad interpuesta por el $25 \%$ del número legal de congresistas de la República contra el primer párrafo de la Primera Disposición Complementaria, Transitoria y Final de la Ley 29944, Ley de Reforma Magisterial).

En la jurisprudencia en cuestión el TC ha reiterado que:

"la remuneración (...) posee una naturaleza alimentaria al tener una estrecha relación con el derecho a la vida, acorde con el principio-derecho a la igualdad y la dignidad, y que al mismo tiempo adquiere diversas consecuencias o efectos para el desarrollo integral de la persona humana" (fundamento 12); y ha agregado que la estructura de este derecho fundamental está compuesta por "el contenido esencial [que] es absolutamente intangible para el legislador, definido desde la teoría institucional, y uno accidental, claudicante ante los límites proporcionados que el legislador establezca a fin de proteger otros derechos o bienes constitucionalmente garantizados"(fundamento 15).

Bajo esta línea de razonamiento, el TC ha definido que el contenido esencial del derecho fundamental a la remuneración comprende los siguientes cinco (5) atributos o elementos ${ }^{3}$ :

a) Acceso, en tanto nadie está obligado a prestar trabajo sin retribución.

b) Impedimento de privación arbitraria, habida cuenta que ningún empleador puede dejar de otorgar la remuneración sin causa justificada.

c) Prioritario, pues su pago es preferente frente a las demás obligaciones del empleador

d) Equidad, al no ser posible la discriminación en el pago de la remuneración.

e) Suficiencia, por constituir el quantum mínimo que garantiza al trabajador y a su familia su bienestar.

3 Síntesis elaborada a partir del Fundamento 16 de la sentencia objeto de comentario. 
Precisamente, sobre este último atributo o elemento, que es el que se relaciona directamente con el derecho explícito a un salario mínimo, el TC ha señalado que:

"la remuneración suficiente, bajo los epígrafes de RMV [remuneración mínima vital] o de salario piso por negociación colectiva, según lo establece el mismo artículo 24 de la Constitución, debe procurar, para él [trabajador] y su familia, el bienestar material y espiritual, es decir, que el trabajador deberá gozar de una existencia conforme a la dignidad humana y que será completada, en caso necesario, por cualesquiera otros medios de protección social"(fundamento 27 ).

Finalmente, el Pleno del TC concluye el análisis de este derecho fundamental precisando en su fundamento 29 que:

"la remuneración suficiente, en tanto parte integrante del contenido esencial del derecho fundamental a la remuneración previsto en el artículo 24 de la Constitución, implica también ajustar su quantum a un criterio mínimo -bien a través del Estado, bien mediante la autonomía colectiva- de tal forma que no peligre el derecho constitucional a la vida o el principio-derecho a la dignidad" (énfasis nuestro).

\section{Sustrato político y social}

El epígrafe que hemos seleccionado para encabezar el presente documento de trabajo sintetiza claramente la idea central de este apartado, y es que como sostiene el profesor Paul Krugman, se suele argüir frecuente y erróneamente -en opinión del Nobel de Economía- que el mercado de trabajo es como cualquier otro mercado de bienes y servicios, por lo que es la "mano invisible" de la oferta y la demanda la que debe determinar el nivel de los salarios.

Por el contrario, afirma Krugman que la decisión sobre qué tanto se paga a los trabajadores depende igual o más de la correlación de las fuerza sociales y la decisión política, como de las leyes del mercado ${ }^{4}$. Señala el ejemplo de lo ocurrido en los Estados Unidos de la segunda post guerra, cuando durante el período denominado "great compression" la intervención directa del Estado a través de la fijación de salarios mínimos y el crecimiento de la sindicalización de la clase obrera lograron reducir la inequidades en el ingreso $\mathrm{y}$, con ello, hicieron crecer $\mathrm{y}$ fortalecer la clase media estadounidense que impulsó la economía en la década del cincuenta.

De hecho, un reciente estudio de la Organización Internacional del Trabajo ha evidenciado casos específicos de países en donde el sueldo mínimo aumentó y tuvo un impacto positivo en la lucha contra la pobreza. Según el estudio en cuestión, en China el salario mínimo creció entre el $8 \%$ y el $13 \%$ en los últimos diez años; en Brasil se

$4 \quad$ Krugman, Paul, 'Walmart's Visible Hand". En: The New York Times, 2 de marzo, 2015. 
incrementó en más del $3 \%$ en promedio y en Camboya casi se triplicó en el mismo período. Por su parte, Alemania destaca por introducir por primera vez en su historia un salario mínimo de 8,50 euros la hora, uno de los más altos en Europa ${ }^{5}$.

En definitiva, el estudio concluye que estos cuatro países han tenido como política común elevar los salarios mínimos de sus trabajadores como una herramienta clave del crecimiento y decisiva para la lucha contra la pobreza.

Siguiendo esta misma posición, en el plano nacional economistas como Félix Jiménez, Bruno Seminario y Pedro Francke se han pronunciado sobre la importancia de contar con una política de salarios mínimos y de incrementarlos periódicamente sobre la base de criterios técnicos.

Así, por ejemplo, afirma Jiménez ${ }^{6}$ que "cuando los trabajadores perciben salarios inadecuados para satisfacer sus necesidades indispensables, se genera un costo social que alguien lo tiene que cubrir. Así, los bajos salarios que contribuyen al deterioro de la capacidad productiva de los trabajadores, son trasladados a la sociedad"; de allí que "el costo social que genera la precariedad del salario y del empleo, se expresa en una baja calidad de las condiciones de vida de la población que, por lo tanto, repercute negativamente en la capacidad productiva y el talento de las generaciones futuras" (énfasis agregado).

Por su parte, Seminario llama la atención sobre el hecho de que en los último ocho años el PBI ha crecido $6.5 \%$ en promedio anual, mientas que el crecimiento del salario real (el poder de compra del trabajador) no ha seguido la misma tendencia, siendo de un $2 \%$ aproximadamente en el mismo periodo; esto supone que "las utilidades de las empresas han crecido más que las remuneraciones y por ello es que el pago al trabajo ha perdido participación en el ingreso nacional" . Agrega que desde 1970 la participación de los trabajadores dependientes en el ingreso nacional ha caído más de 10 puntos porcentuales, pasando de un $40 \%$ a ubicarse actualmente entre 25 y $30 \%$.

Finalmente, y complementando las reflexiones antes citadas, Francke ha recordado que:

"John Maynard Keynes estableció la importancia central que tiene la demanda para la reactivación de una economía golpeada por la crisis, (...) y esa demanda tiene como un componente clave la masa salarial.

5 Ver nota en: http://elcomercio.pe/economia/mundo/que-paises-mundo-subio-massalario-minimo-noticia-1795788

6 Ver nota en: http://www.diariolaprimeraperu.com/online/economia/salarios-y-empleosprecarios-son-excluyentes-y-constituyen-un-costo-social 118600.html

7 Ver nota en: http://gestion.pe/impresa/alza-productividad-se-tradujo-mayor-aumentoutilidades-que-salarios-2089959 
Trabajadores con más ingresos compran más, permiten que las empresas vendan más y de esa manera reactivan la economía y el empleo ${ }^{B}$.

\section{Análisis económico}

\subsection{Evolución de la remuneración mínima}

En el período 1973 - 1991, la remuneración mínima (RM) se contrajo fuertemente en nuestro país, perdiendo el $87,4 \%$ de su valor real ${ }^{9}$, en tanto el producto bruto interno (PBI) per cápita ${ }^{10}$ se redujo "sólo" en 24,2\%.

Posteriormente, en la década del noventa la RM real duplicó su valor, mientras que en el período 2001-2013 mantuvo un crecimiento moderado, incrementándose a una tasa promedio anual de 2,4\%; en tanto el PBI per cápita creció a una tasa promedio anual de $4.5 \%$, como se puede apreciar en el gráfico $\mathrm{N}^{\circ} 1$.

\section{Gráfico $N^{\circ} 1$}

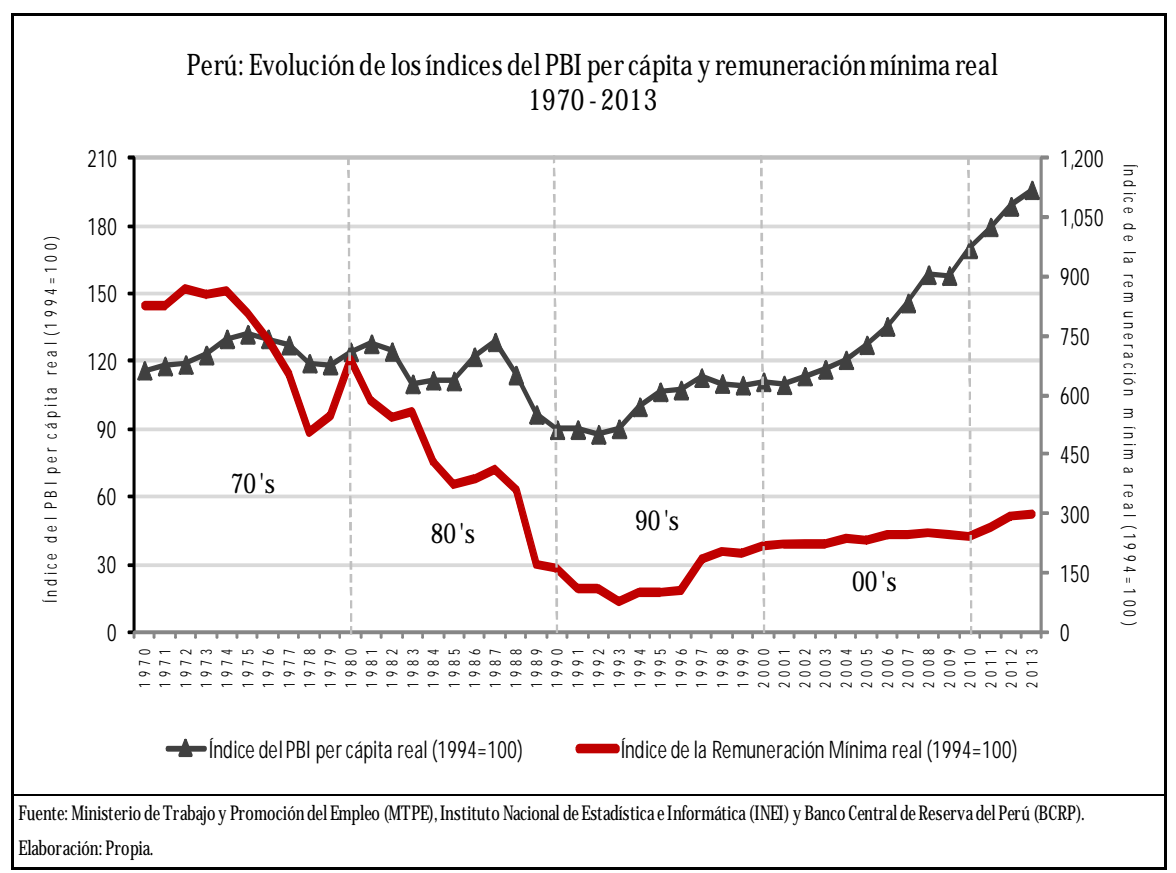

8 Ver nota en: http://elcomercio.pe/opinion/columnistas/debate-se-aumentarremuneracion-minima-vital-noticia-1794147

$9 \quad$ Se refiere a su poder adquisitivo.

10 Se refiere al PBI per cápita real. 
De esta manera, a pesar de la recuperación de la RM real observada en los últimos 20 años, su valor en el año 2013 representa apenas el 34,4\% de la RM real registrada en el año 1972.

Si comparamos la evolución de la RM en Perú con la registrada en otros países de la región en la última década, apreciamos que Honduras casi triplicó el valor real de su RM, Uruguay lo incrementó en 156,1\%, Nicaragua en 87,3\%, Brasil en 79,9\%, Ecuador en $42,1 \%$ y Bolivia en 38,5\%; mientras que Perú aumentó su RM en 32\%, a pesar del significativo crecimiento económico registrado $(96,7 \%)$, como se observa en el gráfico $N^{\circ} 2$.

\section{Gráfico $\mathbf{N}^{\circ} 2$}

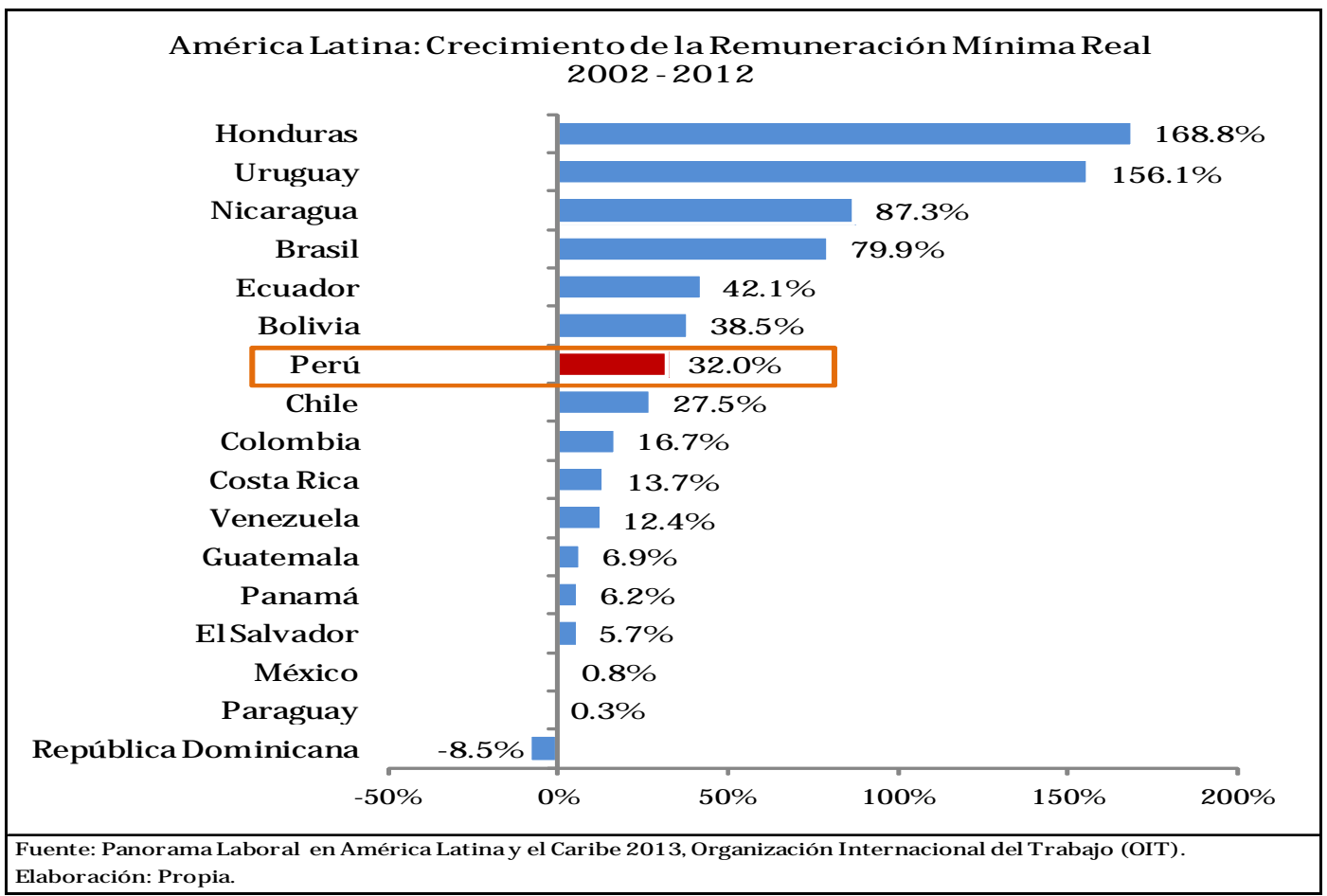

De otro lado, las remuneraciones mínimas con mayor poder adquisitivo son las de Argentina, Paraguay y Ecuador; mientras que las de menor poder adquisitivo son las de México, Nicaragua y Bolivia. La RM de Perú se mantiene en un rango medio, como se desprende del gráfico $\mathrm{N}^{\circ} 3^{11}$.

11 La comparación se realiza utilizando la metodología de paridad en el poder adquisitivo (PPP por sus siglas en inglés). 


\section{Gráfico $\mathbf{N}^{\circ} 3$}

América Latina: Remuneración Mínima en dólares PPP

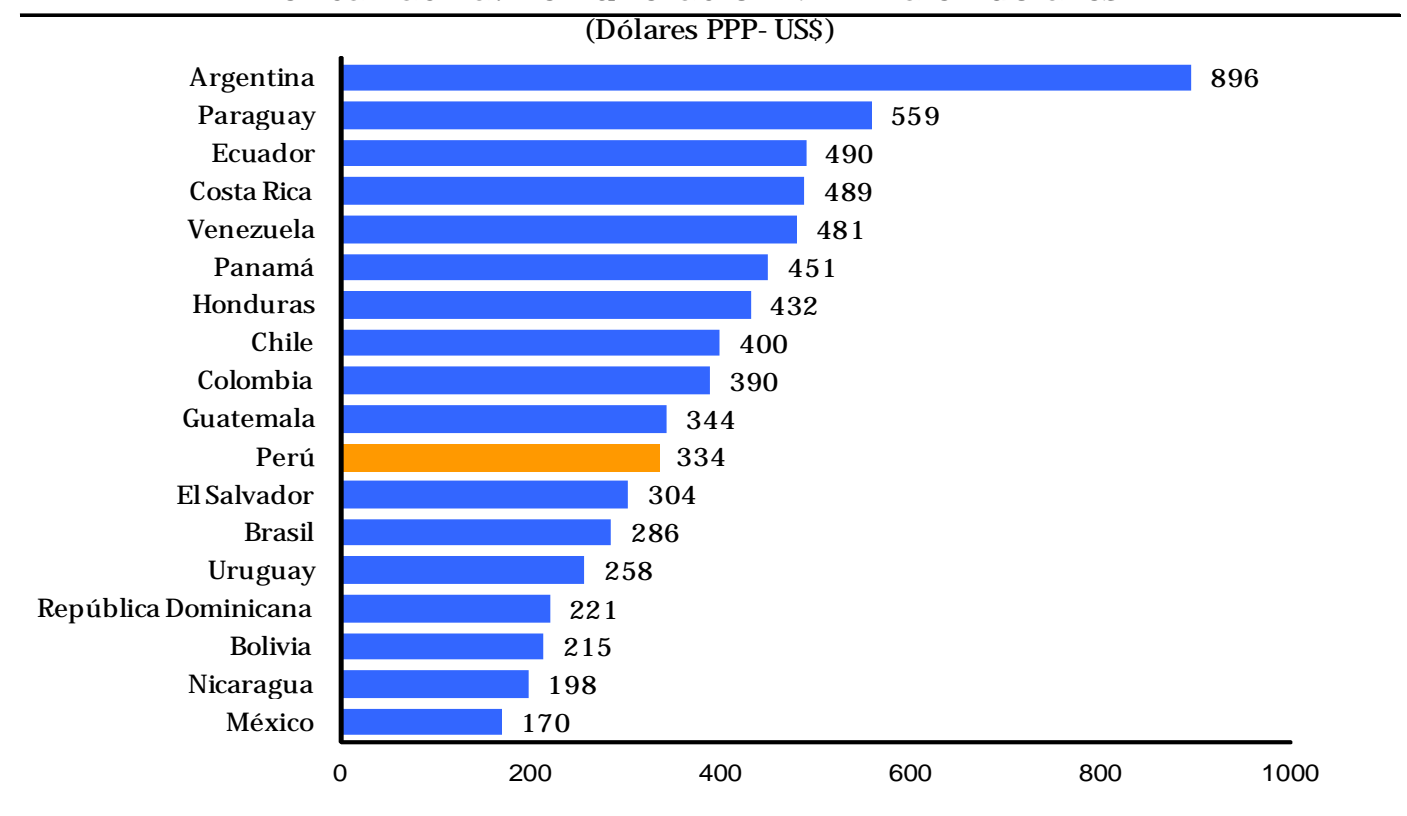

Fuente: Informe mundial sobre salarios 2010/2011: Políticas salariales en tiempos de crisis (OIT). Elaboración: Propia.

\subsection{Mecanismo de revisión de la Resolución Ministerial aprobado por el CNTPE}

Conforme al marco normativo, en la Sesión Extraordinaria No 25 del 23 de agosto de 2007, el Pleno del Consejo Nacional de Trabajo y Promoción del Empleo (CNTPE) aprobó el Informe "Crecimiento de la Productividad y Reajuste del Salario Mínimo", que prevé un mecanismo de revisión bienal de la RM en función a la inflación subyacente proyectada (indicador que predice la inflación tendencial, es decir, aquella que excluye a los productos cuyos precios son muy volátiles) y la productividad multifactorial (variable que mide la eficiencia del aparato productivo):

\section{$\Delta \mathbf{R M}=\Pi^{\mathrm{s}}+\Delta \mathbf{q}$}

Donde:

$\mathbf{R} \mathbf{R}$ : Variación porcentual de la remuneración mínima.

$\Pi^{s} \quad$ : Inflación subyacente proyectada.

$\boldsymbol{\Delta} \mathbf{q}$ : Variación porcentual de la productividad multifactorial. 
La referida fórmula busca proteger el poder adquisitivo de los trabajadores que perciben la RM sin generar presiones inflacionarias, dado que el incremento de dicha remuneración acompañará el proceso inflacionario y no lo replicará en un período posterior. Asimismo, tiene por objetivo trasladar parte de las mayores ganancias empresariales generadas por la mayor eficiencia de los factores de producción (principalmente capital y trabajo) a los trabajadores que participaron en dicho proceso.

Cabe agregar que el citado mecanismo de revisión de la RM incluye una cláusula de "gatillo", la cual considera aplicar un incremento automático adicional en la RM cuando la tasa de inflación subyacente efectiva al final del período de referencia (un año) supere significativamente la tasa de inflación subyacente proyectada que se utilizó en el cálculo del último incremento de la RM.

Asimismo, los resultados de la aplicación de la fórmula serán viables siempre que no se presente ninguna de las siguientes situaciones:
a) Profunda recesión;
b) Fuerte elevación de la tasa de desempleo abierto;
c) Fuerte elevación de la tasa de informalidad laboral; o
d) Alza desmedida en la relación remuneración mínima / remuneración promedio.

\subsection{Importancia del mecanismo de revisión de la Resolución Ministerial aprobado por el CNTPE}

Resulta indispensable concluir con la aplicación de incrementos discrecionales en la RM. Para ello, se debe seguir el enfoque que consiste en vincular los incrementos salariales a una mayor productividad y competitividad. El proceso de apertura comercial que atraviesa el Perú requiere, necesariamente, que tanto las relaciones laborales entre empresas y trabajadores, como las políticas salariales en el sector privado, se vinculen a aumentos de la competitividad y productividad. En ese contexto, la metodología de revisión de la RM del CNTPE se adecua a la realidad económica del país, lo cual permite darle sostenibilidad al mecanismo. Con ello, mientras menos discrecional sea la determinación del incremento de la RM, menor será la distorsión que podría generar en el mercado de trabajo.

Asimismo, el tener una periodicidad establecida y criterios objetivos de ajuste, le otorgan predictibilidad al mecanismo aprobado por el CNTPE, lo cual disminuye la incertidumbre en los agentes económicos. En tanto, los factores que determinan si existe el escenario económico adecuado para incrementar la RM, le otorgan flexibilidad a la política de RM. 
De otro lado, los aumentos de la RM sobre la base de criterios técnicos, permitirán que recupere en el mediano plazo su capacidad adquisitiva, acercándose al valor de la canasta básica de consumo de un hogar ${ }^{12}$.

Es importante agregar que la RM es un instrumento eficiente que cumple un rol fundamental en la determinación del salario base dentro de la escala remunerativa de una empresa, especialmente en mercados laborales que cuentan con sistemas de negociación colectiva poco desarrollados, como es el caso del Perú.

Finalmente, la RM puede ser concebida como un instrumento que incide en el aumento del consumo interno y por ende, en el crecimiento de la demanda interna.

\subsection{Aplicación del mecanismo de revisión de la Resolución Ministerial}

Aplicando la metodología de revisión de la RM aprobada por el CNTPE, desde el 1 de junio del 2014, la RM debería haberse incrementado en 14,5\%, es decir, en S/. 109, pasando de S/. 750 a S/. 859, conforme se detalla a continuación (ver gráfico $N^{\circ} 4$ ):

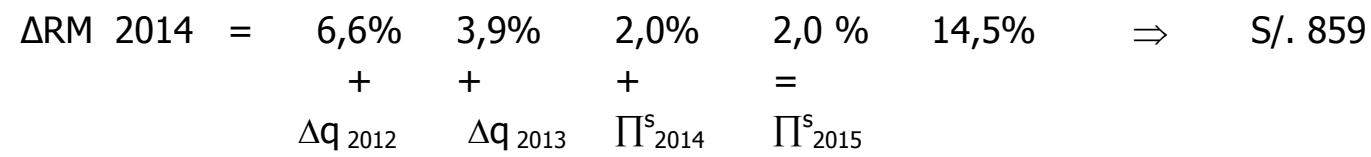

Donde:

ARM 2014 Incremento porcentual de la remuneración mínima en el año 2014.

$\Pi^{5} \mathbf{2 0 1 4}$ Inflación subyacente proyectada para el año 2014.

$\Pi^{s} \mathbf{2 0 1 5}$ Inflación subyacente proyectada para el año 2015.

$\Delta \mathbf{q} 2012$ Incremento porcentual de la productividad multifactorial en el año 2012

$\Delta \mathbf{q} 2013$ Incremento porcentual de la productividad multifactorial en el año 2013

Cabe precisar que el incremento porcentual de la productividad multifactorial se calcula utilizando la metodología descrita en el informe: "Crecimiento de la productividad y reajuste del salario mínimo", aprobado por el CNTPE en la Sesión Extraordinaria No 25 en el año $2007^{13}$; mientras que las proyecciones de inflación han sido tomadas del

12 Actualmente la RM representa poco más de la mitad del valor de la canasta básica de consumo familiar (52,3\%). Fuente: Encuesta Nacional de Hogares sobre Condiciones de Vida y Pobreza (ENAHO), Instituto Nacional de Estadística e Informática (INEI).

13 El informe está disponible en la página web del MTPE: http://www.mintra.gob.pe/archivos/file/CNTPE/Crecimiento\%20de\%20la\%20productivida d\%20y\%20reajuste\%20del\%20salario\%20minimo.pdf 
Reporte de inflación de diciembre de 2013, publicado por el Banco Central de Reserva del Perú (BCRP) $)^{14}$.

\section{Gráfico $N^{\circ} 4$}

Incrementos realizados en la RM por Decreto Supremo post aprobación del mecanismo de revisión de la RM del CNTPE

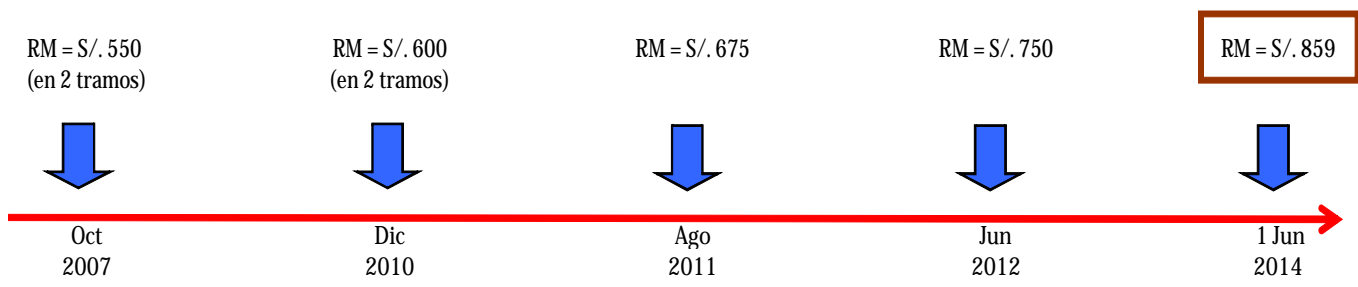

La metodología de revisión de la RM acordada por el CNTPE, contempla reevaluar el incremento propuesto si no existe un contexto adecuado, sin embargo, la información estadística disponible permite afirmar que:

- No existe un escenario de profunda recesión, ya que el PBI peruano creció en $2,4 \%$ en el $2014^{15}$ y según el $\mathrm{BCRP}^{16}$ y el $\mathrm{MEF}^{17}$, el PBI crecería en $4,8 \%$ y $6,0 \%$ en el 2015, respectivamente.

- $\quad$ En lo que respecta a la tasa de desempleo a nivel nacional, no se ha elevado fuertemente, por el contrario, viene decreciendo, al pasar de 5,4\% en el 2005 a 4,0\% en el 2013, según la Encuesta Nacional de Hogares sobre Condiciones de Vida y Pobreza (ENAHO) del INEI; mientras que en el ámbito urbano disminuyó de $7,4 \%$ a $4,8 \%$ en el mismo período. En tanto para Lima Metropolitana, entre el cuarto trimestre del 2005 y 2014, la tasa de desempleo se redujo de $8 \%$ a 5,6\%, según la Encuesta Permanente de Empleo del INEI;

- La tasa de informalidad labora ${ }^{18}$ tampoco se elevó fuertemente, sino que mostró una importante reducción en los últimos años, al pasar de 68,8\% en el 2005 a

14 El informe está disponible en la página web del Banco Central de Reserva del Perú (BCRP):http://www.bcrp.gob.pe/docs/Publicaciones/ReporteInflacion/2013/diciembre/reporte-de-inflacion-diciembre-2013.pdf

15 Fuente: INEI y BCRP.

16 Según el Reporte de Inflación de enero de 2015, elaborado por el BCRP: http://www.bcrp.gob.pe/docs/Publicaciones/Reporte-Inflacion/2015/enero/reporte-deinflacion-enero-2015.pdf

17 Según el Marco Macroeconómico Multianual Revisado 2015-2017, elaborado por el Ministerio de Economía y Finanzas (MEF):

http://www.mef.gob.pe/contenidos/pol econ/marco macro/MMM2015 2017 Rev.pdf 
$57,4 \%$ en el 2013 a nivel nacional, según el INEI; en tanto que a nivel urbano disminuyó de $65,3 \%$ a $53,5 \%$ en el mismo período ${ }^{19}$; y

- El ratio remuneración mínima / remuneración promedio en el sector privado formal nacional no ha registrado un alza desmedida, por el contrario, se mantiene en niveles bajos a pesar de los últimos incrementos realizados en la RM. En el período enero 2008 - diciembre 2012, dicho ratio se mantuvo en alrededor del 36\%, mientras que entre enero y diciembre de 2013 su valor promedio fue de $37,6 \%$ y entre enero y junio de 2014 fue de $36,1 \%$ en promedio $^{20}$.

En conclusión, sobre la base de la metodología de revisión de la RM aprobada por el CNTPE, podemos afirmar que un incremento de S/. 109 en la RM (de S/. 750 a S/. 859), no generaría mayores distorsiones en la economía ni en el mercado de trabajo.

\subsection{Beneficiarios $y$ efectos en el empleo formal y remuneraciones del incremento de la Resolución}

Un incremento de la RM en S/. 109 (de S/. 750 a S/. 859) beneficiaría directamente a 774224 trabajadores formales a nivel nacional, 9008 en el sector público ${ }^{21}$ y 765216 en el sector privado ( $24,9 \%$ del universo formal en el último caso). En el ámbito privado, el 53,3\% de los beneficiados se desempeña en empresas de 1 a 10 trabajadores, el $22,7 \%$ en empresas de 11 a 100 trabajadores y el $24,1 \%$ en empresas de101 a más trabajadores ${ }^{22}$.

Luego del último incremento de la RM, realizado en junio de 2012 (de S/. 675 a S/. 750), el empleo formal privado no se redujo, por el contrario, continuó mostrando resultados positivos en todos los tamaños de empresa. Según la Encuesta Nacional de Variación Mensual del Empleo del MTPE, en el periodo julio - agosto del 2012 (meses post incremento de la RM), el empleo formal urbano en empresas privadas de 10 a más trabajadores creció $4,4 \%$ respecto a igual periodo del 2011 , tasa similar a la registrada en meses anteriores (ver gráfico $\mathrm{N}^{\circ} 5$ ).

18 La tasa de informalidad laboral se calcula considerando al porcentaje de los asalariados del sector privado no registrados en la planilla de las empresas donde laboran.

Fuente: ENAHO, INEI.

Fuente: Planilla Electrónica, MTPE.

Incluye sólo a los trabajadores sujetos al régimen laboral privado (Decreto Legislativo 728).

Fuente: Planilla Electrónica, MTPE. 


\section{Gráfico $\mathbf{N}^{\circ} 5$}

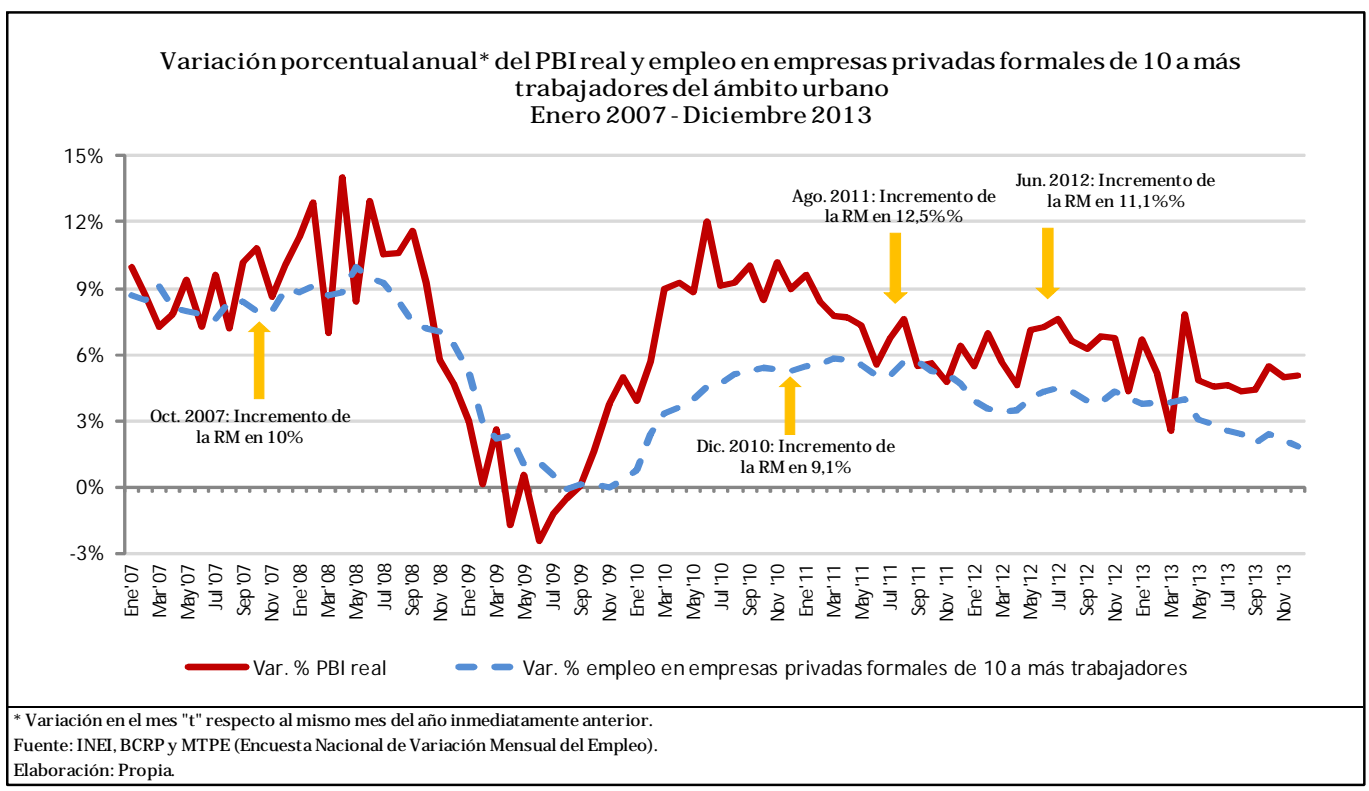

Asimismo, en el período julio - agosto del 2012, meses posteriores al último incremento de la RM, se generaron 58314 empleos netos en el sector privado formal, de los cuales $44548(76,4 \%)$ se crearon en empresas de 101 a más trabajadores, 5 $535(9,5 \%)$ en empresas de 11 a 100 trabajadores y $8231(14,1 \%)$ en empresas de 1 a 10 trabajadores $^{23}$, como se aprecia en el gráfico $N^{\circ} 6$. 


\section{Gráfico $N^{\circ} 6$}

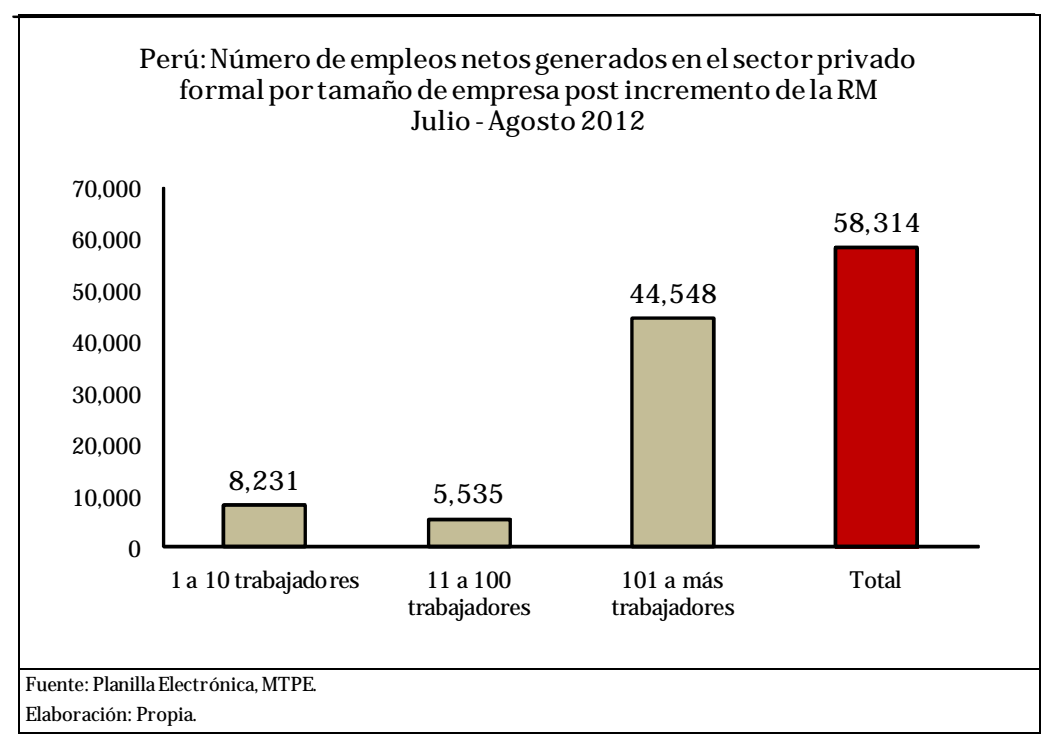

Cabe agregar que según la Planilla Electrónica, en agosto del 2012 (mes post incremento de la $\mathrm{RM}$ ) el empleo formal en el sector privado creció en $2 \%$ respecto a junio del 2012 (mes en el que se registró el incremento de la RM). Incluso en el período junio - agosto del 2012, el crecimiento mensual del empleo formal mostró cifras positivas, reflejando que en los meses post incremento de la RM la generación de empleo no se vio afectada por la mayor RM, como figura en el gráfico $\mathrm{N}^{\circ} 7$.

\section{Gráfico No 7}

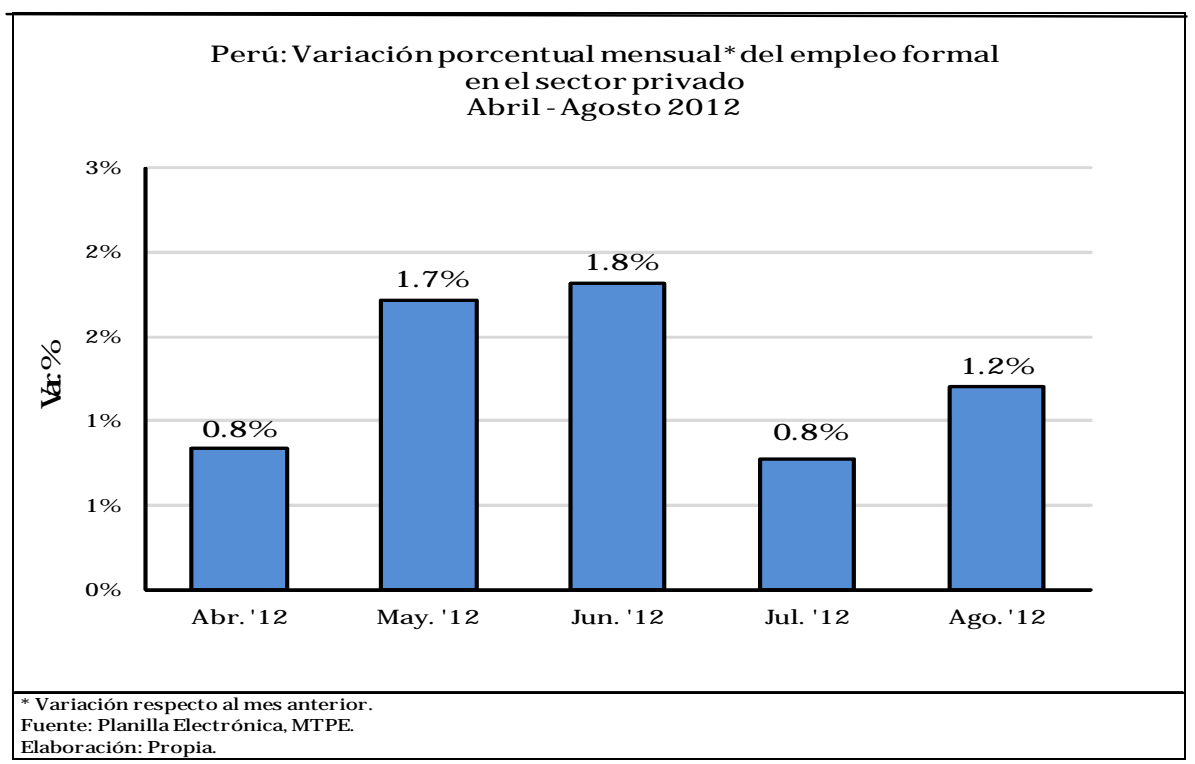


Si nos enfocamos en el ámbito de las empresas de menor tamaño ( 1 a 10 trabajadores), podemos apreciar que en el período post incremento de la RM (julio agosto del 2012) el crecimiento mensual del empleo formal continuó siendo positivo, reflejando que el empleo en dicho sector tampoco se vio afectado por la mayor RM, como se desprende del gráfico $\mathrm{N}^{\circ} 8$.

\section{Gráfico $\mathbf{N}^{\circ} 8$}

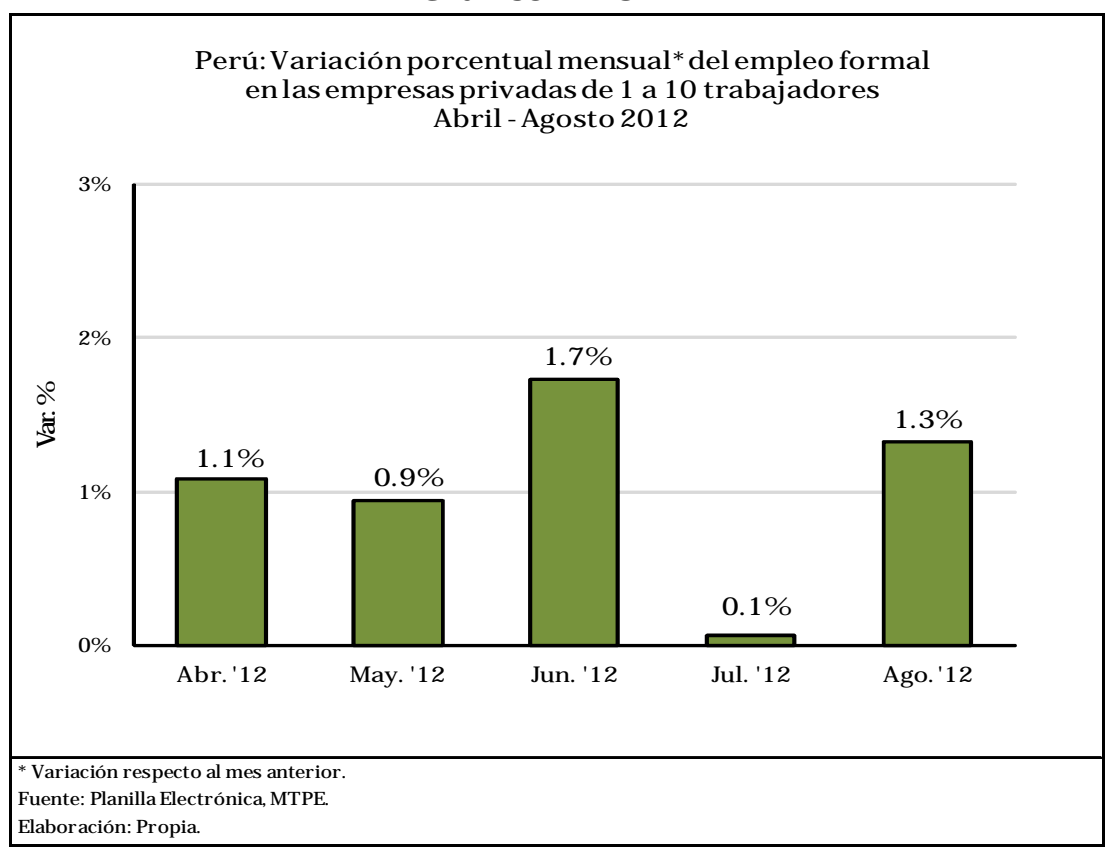

De otro lado, es importante precisar que los incrementos de la RM realizados en el período $2004-2013$, han ido a la par con una significativa reducción del porcentaje de trabajadores asalariados del sector privado que perciben una remuneración inferior a la mínima, considerando que dicho porcentaje disminuyó de $45,8 \%$ a $34,1 \%$ a nivel nacional en el referido período ${ }^{24}$.

Esta reducción se ha registrado en todo tamaño de empresa: de $64 \%$ a $54 \%$ en las empresas de 1 a 10 trabajadores, de $32 \%$ a $24,2 \%$ en las empresas de 11 a 100 trabajadores y de $13,1 \%$ a $8,8 \%$ en las empresas de 101 a más trabajadores ${ }^{25}$.

En lo que respecta al nivel de ingresos, las remuneraciones promedio reales en el sector privado formal vienen mejorando desde enero del 2011, llegando a crecer $11,9 \%$ entre diciembre del 2010 (mes a partir del cual se realizaron los aumentos más

\footnotetext{
24 Fuente: ENAHO, INEI.

25 Fuente: ENAHO, INEI.
} 
próximos en la RM) y octubre del $2013^{26}$, permitiendo concluir que los recientes incrementos de la RM han incidido positivamente en la recuperación de los niveles remunerativos en el país, que se habían visto estancados en los últimos 20 años (ver gráfico $\mathrm{N}^{\circ}$ 9).

\section{Gráfico $N^{\circ} 9$}

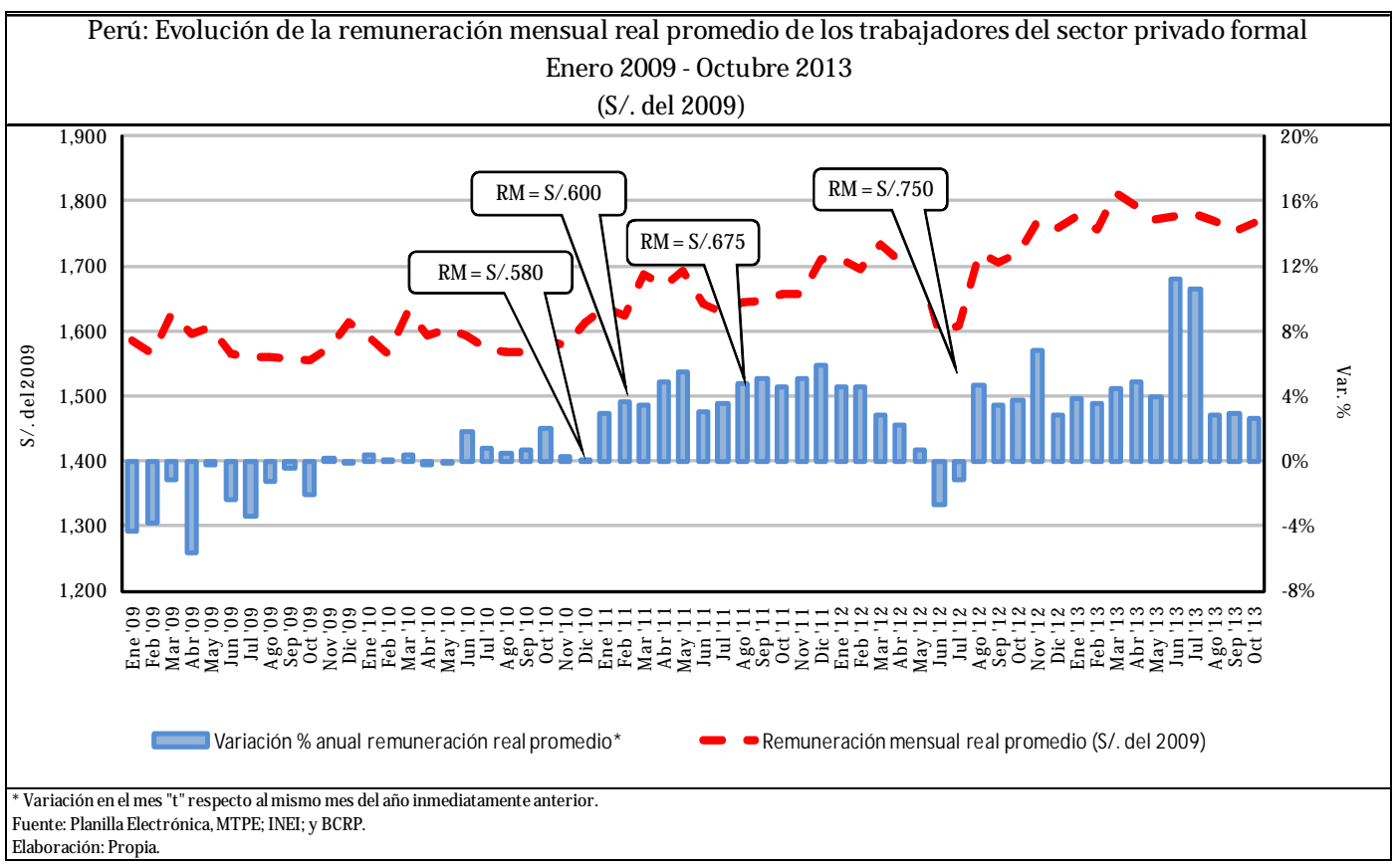

En tal sentido, cabe precisar que en los períodos donde no hubo incremento de la RM, las remuneraciones promedio reales se mantuvieron estancadas e incluso se redujeron. Así, según la Planilla Electrónica del MTPE, en el 2010 las remuneraciones reales mensuales promedio en el sector privado formal crecieron sólo en $0.5 \%$ respecto al 2009, en tanto en el 2009 se contrajeron en $-2.1 \%$ respecto al 2008.

Finalmente, debemos agregar que la recuperación de los niveles remunerativos en el sector privado formal se dio en todos los segmentos empresariales, ya que en octubre del 2013 las remuneraciones promedio reales en las empresas de 1 a 10 trabajadores crecieron en 17,3\% respecto a diciembre del 2010 (mes a partir del cual se realizaron los incrementos más recientes en la RM), en tanto, en las empresas de 11 a 100

Fuente: Planilla Electrónica, MTPE. 
trabajadores y de 101 a más trabajadores, las remuneraciones promedio reales crecieron en $10,6 \%$ y $11 \%$, respectivamente, como se desprende del gráfico $\mathrm{N}^{\circ} 10^{27}$.

\section{Gráfico $\mathbf{N}^{\circ} 10$}

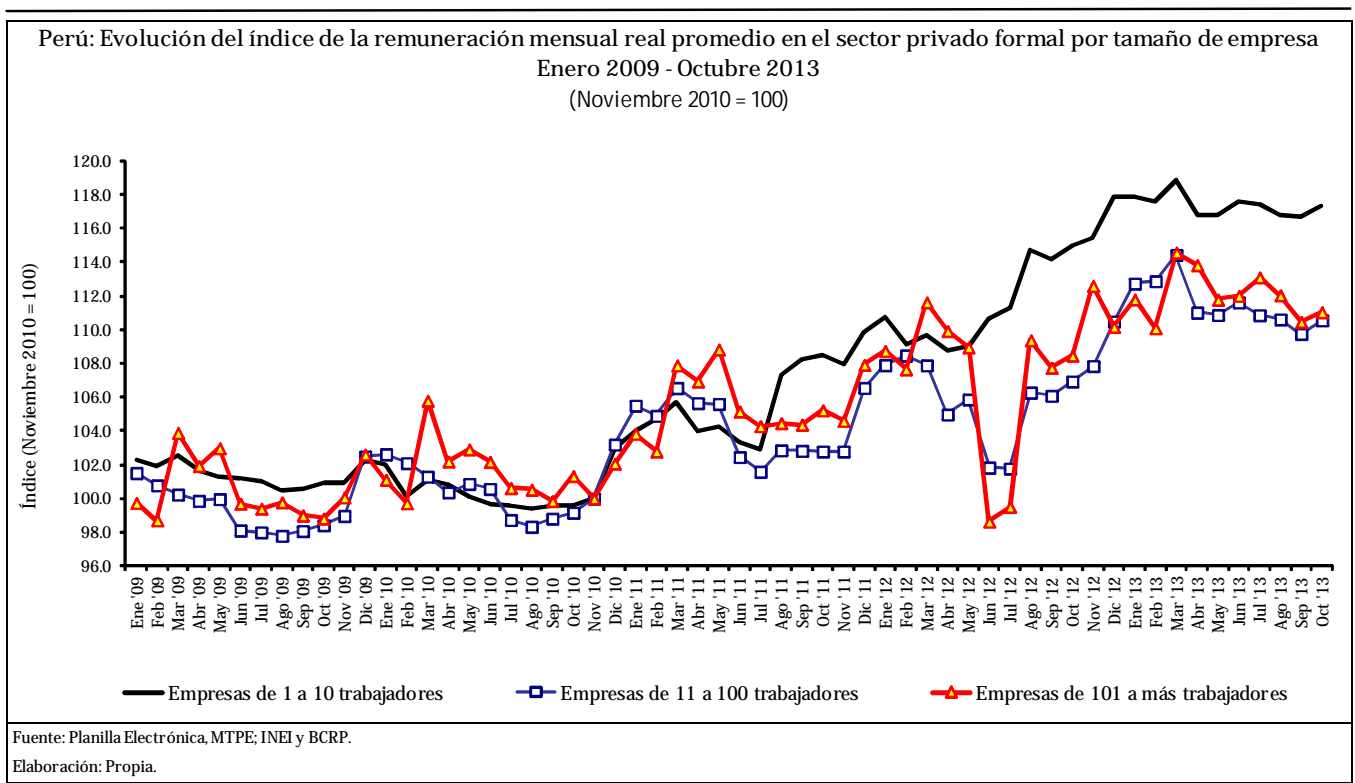

\section{Conclusiones}

a) El derecho constitucional a una remuneración mínima y la obligación del Estado de regular su incremento forman parte de un conjunto de derechos humanos fundamentales reconocido en los principales instrumentos internacionales ratificados por el Estado peruano, a la par que constituyen en la actualidad elementos prioritarios en el marco de los procesos de apertura al libre comercio de los que el Peru viene siendo parte desde hace una década.

b) El sueldo no es un simple "precio", porque el trabajador no es un simple "bien" o "servicio" en el mercado; de allí que sea un error considerar que es la "mano invisible" de la oferta y la demanda la que debe determinar el nivel de los salarios. Por el contrario, la decisión sobre la existencia y nivel de los saliros mínimos depende de la correlación de las fuerzas entre los actores sociales y la decisión política.

c) A pesar de la recuperación de la remuneración mínima real observada en los últimos 20 años, su valor en el año 2013 representa apenas el 34,4\% de la remuneración mínima real registrada en el año 1972. Por ello, resulta indispensable desterrar mecanismos de aplicación de incrementos discrecionales en la remuneración mínima, para lo cual se debe seguir el enfoque que consiste

27 Fuente: Planilla Electrónica, MTPE. 
en vincular los incrementos salariales a una mayor productividad y competitividad.

d) Precisamente, el CNTPE cuenta ya con un mecanismo de revisión bienal de la remuneración mínima en función a la inflación subyacente proyectada y la productividad multifactorial, fórmula que busca proteger el poder adquisitivo de los trabajadores sin generar presiones inflacionarias, a la par que otorgar predictibilidad y flexibilidad al mecanismo de ajuste.

e) Sobre la base del análisis realizado en el presente artículo, podemos concluir que el CNTPE debería proponer un incremento de S/. 109 en la remuneración mínima (de S/. 750 a S/. 859), lo cual no generaría mayores distorsiones en la economía ni en el mercado de trabajo; por el contrario, mejoraría directamente las remuneraciones de 774224 trabajadores formales a nivel nacional, 765216 en el sector privado y 9008 en el sector público. 